\title{
MODELAGEM CARTESIANA E ERGONOMIA APLICADAS NA CONSTRUÇÃO DE FIGURINOS DE DANÇA ADEQUADOS PARA PESSOAS COM NECESSIDADES ESPECÍFICAS
}

\author{
THEIS, Mara Rubia (1); \\ MARDULA, Emanoela (2); \\ TARACHUCKY, Laryssa (3) \\ (1) IFSC - Instituto Federal de Educação, Ciência e Tecnologia de Santa Catarina, Pós \\ graduação em PROEJA \\ e-mail:marubiat@ifsc.edu.br \\ (2) IFSC - Instituto Federal de Educação, Ciência e Tecnologia de Santa Catarina, Técnico \\ em Moda \\ e-mail: emanoela@ifsc.edu.br \\ (3) IFSC - Instituto Federal de Educação, Ciência e Tecnologia de Santa Catarina, Mestrado \\ em Design \\ e-mail: laryssa@ifsc.edu.br

\begin{abstract}
RESUMO
Este artigo apresenta a técnica de modelagem cartesiana aplicada à construção de figurinos para os bailarinos do grupo de dança da APAE de Jaraguá do Sul. Os usuários deste grupo apresentam necessidades específicas em diferentes graus e biótipos corporais com variações anatômicas que devem ser analisadas individualmente, com objetivo de oportuniza-los figurinos de dança que estimulem sua autonomia. O foco de desenvolvimento destas peças é a adequação do produto do vestuário à anatomia dos bailarinos para melhorar o desempenho de suas apresentações, atentando para a segurança, o conforto estético e emocional, a facilidade de manuseio e a usabilidade.
\end{abstract}

Palavras-chave: modelagem cartesiana, ergonomia, antropometria, necessidades específicas, vestuário.

\begin{abstract}
This article presents the Cartesian modeling technique applied to the construction of costumes to the dancers from APAE Jaraguá do Sul. The users from this group have different degrees of disabilities and body biotypes with anatomical variations that must be analyzed individually in order to create opportunities for them to develop dance costumes that encourage autonomy. The focus of the development of these pieces is the adequacy of the product to the dancers' anatomy in order to improve their performance, paying attention to safety, aesthetic and emotional comfort, ease of handling and usability.
\end{abstract}


Keywords: Cartesian modeling, ergonomics, anthropometry, disabilities, clothing.

\section{INTRODUÇÃO}

A discussão sobre moda, modelagem, criação e demais assuntos relacionados partem de uma mesma estrutura, individual e coletiva: o corpo. Embora exista grande variedade de corpos, proporções e biótipos sob a pele de diferentes personalidades, individualidades e anseios, todo corpo pode ser bem vestido (CASTILHO; VICENTINI, 2010; GRAVE, 2010). Para tanto, faz-se necessário desenvolver um raciocínio lógico no processo de ensino e aprendizagem da construção do vestuário, partindo do entendimento dessa massa corpórea tridimensional, composta por articulações, cujas partes estão em constante movimento, que significa e tem significados, e que, acima de tudo, é sensível, frágil e complexa em emoções e linguagens.

Partindo do entendimento do ser humano além do manequim industrial ou do papel liso e bidimensional, a indústria da moda tem a complexa missão de projetar e construir, em um ritmo cada vez mais acelerado, vestes para corpos desiguais. Este artigo apresenta a Modelagem Cartesiana como metodologia que faz uso de uma linguagem matemática objetiva, aplicando estudos básicos do corpo humano e relacionando antropometria e ergonomia ao desenvolvimento de moldes para qualquer corpo ou biótipo físico, independentemente de gênero e faixa etária. Tal metodologia é apresentada por meio da análise de sua aplicação no desenvolvimento de figurinos de dança para pessoas com necessidades específicas.

\section{CORPO HUMANO, DIVERSIDADE EM MOVIMENTO}

O corpo é constituído por configurações biomorfológicas que sofrem alterações pelas diversas possibilidades combinatórias das características étnicas e genéticas que lhe conferem particularidades em relação à sua própria constituição e construção biomorfológica. Assim podemos entender tais diferenças como traços distintivos entre as raças, que se particularizam por singularidades fisionômicas e anatômicas. A fim de se justificar essas particularidades, basta que sejam mencionadas as diversas tonalidades da pele (aspecto cromático), tipologia e textura da epiderme (aspecto matérico), altura, volume e proporção (aspecto topológico), e as formas do corpo (aspecto eidético), que, numa tentativa de reagrupamento, podem ser tratadas como características distintivas pertinentes a diferentes raças. (CASTILHO, 2004, P.54).

A evolução permitiu ao homem tornar-se um ser vertical, ereto e capaz de iniciar uma organização social, desenvolver métodos de proteção e instituir direitos e padrões comportamentais, bem como classificar os indivíduos segundo sua "normalidade física e mental", definindo se o indivíduo é são ou deficiente ${ }^{1}$ (GRAVE, 2010). O conhecimento da

1 O entendimento social dessas classificações do indivíduo pode ser ampliado ao consultar o verbete "deficiente" em fontes como o Dicionário Michaelis de Língua Portuguesa, que o traduz como sinônimo de pessoa ou coisa falha, imperfeita ou incompleta. 
forma e das medidas do corpo aplicado a projetos é denominado antropometria, termo não exclusivo dos estilistas de moda, também utilizado em quaisquer tipos de projetos, que podem ser de cidades, de edifícios e de mobiliário (BOUERI, 2008, p. 347).

Em qualquer desenvolvimento de produtos é fundamental o conhecimento das medidas do corpo ou perfil do público que fará uso do mesmo, e para a obtenção das medidas antropométricas de forma adequada é necessário desenvolver técnicas e analisar os instrumentos adequados ${ }^{2}$. Para lida (2005), a antropometria é apresentada em três áreas principais: a antropometria estática, que deve obter as medidas do corpo parado ou em poucos movimentos, com medições entre pontos anatômicos bem identificados; a antropometria dinâmica, que obtém a medida dos alcances dos movimentos, ou seja, cada parte de corpo são medidas durante uma atividade; e a antropometria funcional, quando são executadas atividades específicas, observando cada parte do corpo. Boueri (2008) apresenta a antropometria subdividida em duas áreas: antropometria estática ou estrutural, na qual a medida é obtida sem mover o corpo, indicada para peças de alfaiataria e do segmento social; e a antropometria dinâmica ou funcional, cujas medidas são obtidas quando o corpo está em movimento em determinada atividade, voltada para a modelagem de peças do vestuário esportivo.

De acordo com Grave (2010), a moda industrializada distancia o corpo de seu verdadeiro sentir, pensar, agir e movimentar, ignorando as diferenciações que o corpo humano apresenta. Segundo Neves et al. (2014, p.6), no âmbito das reformulações plásticas corporais, por sua capacidade de materializar a subjetividade de cada indivíduo, o produto de moda promove o redesign do corpo possibilitando que o usuário faça seu uso de maneira a driblar eventuais configurações corpóreas não aceitas. Ou seja, para o desenvolvimento adequado dos artigos na indústria do vestuário e na área de design de moda, faz-se necessário o conhecimento do corpo através de sua observação, obtenção das medidas e análise do movimento corporal.

A aplicabilidade da ergonomia ao desenvolvimento da indumentária pode ter suas premissas juntamente às necessidades humanas de cobrir o corpo, seja por questões sociais, culturais ou climáticas, adaptando a ele uma "segunda pele". Contudo, na sociedade contemporânea, a moda vem enfatizando-a como ferramenta amplificadora da comunicação e da linguagem corporal, transformando-se em uma importante ferramenta de expressão pessoal e tornando-se uma extensão do próprio corpo.

Se partirmos dos pressupostos de que o vestuário é intrínseco à vida humana e que o objetivo principal da ergonomia é adaptar o que está a volta dos seres humanos às suas necessidades, é válido justificar também a adaptação das roupas, de forma que elas ofereçam conforto, mobilidade, bom caimento, segurança, e ainda sejam confortáveis para o usuário. Isso significa que antes de se ter uma interface com qualquer coisa que esteja

\footnotetext{
${ }^{22}$ No Brasil, existem normas para a obtenção dessas medidas, como a NBR 15127/2004, para medidas do corpo de forma sequencial, com definições e as indicações das partes do corpo a serem mensuradas, e a NBR 13377/1995, que sugere a padronização das medidas do corpo humano para vestuário. Apesar da existência dessas normas, devido à necessidade de controle dos custos de fabricação, o mercado de moda ainda apresenta tabelas dimensionais limitadas em seus artigos do vestuário, focando em determinados perfis em detrimento de outros.
} 
no entorno dos usuários, as pessoas se relacionam com as suas vestimentas. (SABRA, 2009, p.43-44).

Devido à grande diversidade de biótipos e mudanças antropométricas, seja este corpo são ou deficiente, cresce a necessidade de técnicas de modelagem que permitam aos profissionais de moda atuar no desenvolvimento de vestimentas bem adaptadas ao corpo, que atendam às funções de segurança, conforto, funcionalidade e estética.

\section{MODELAGEM DO VESTUÁRIO}

A modelagem está para o design de moda, assim como a engenharia está para a arquitetura. (TREPTOW, 2007, p.154).

Para desenvolver uma modelagem, Sabra (2009) defende a necessidade de se obter as medidas do corpo a serem empregadas na sua construção, relacionando-as diretamente com a função da peça de vestuário em vestir a parte superior ou inferior do corpo. As medidas básicas para o desenvolvimento de moldes superiores são as medidas de circunferência de tórax e busto. Já para as moldes de peças inferiores são utilizadas as medidas de circunferência de quadril e cintura. Treptow (2007) destaca dois processos para modelar: a moulage, proveniente da alta-costura e utilizada na indústria fazendo uso de manequins industriais padronizados; e a modelagem plana, método que desenvolve um diagrama que reproduz em duas dimensões as curvas do corpo humano.

A técnica de moulage também é conhecida nos países de língua inglesa como draping. Essa técnica de modelar os tecidos diretamente sobre o corpo humano ou de um manequim é muito utilizada na alta costura por possibilitar a visão da peça praticamente pronta, instantaneamente, trazer a noção real de seu caimento, volumes e proporções, e analisar a localização de folgas ${ }^{3}$, pences ${ }^{4}$ e recortes, otimizando o tempo de concepção e elaboração e ampliando o conhecimento do profissional de moda quando às estruturas corpóreas junto à vestimenta. Atualmente, a moulage é utilizada para fins diversos como a elaboração de moldes base, a interpretação de modelos já existentes ou como instrumento de criação.

A modelagem plana é basicamente o ato de planificar o corpo humano em escala real construindo o molde base, modelagem anatômica, respeitando as medidas obtidas na mensuração do corpo, para depois acrescer as medidas de costura e folgas necessárias, construí-lo em tecido, vesti-lo, aprová-lo e/ou desenvolver acertos. Após obter a aprovação da modelagem base, esta é utilizada para construir outros moldes. Na indústria, esse processo deve ser simplificado, de fácil compreensão e manuseio, a fim de ser utilizado em outros setores, como os de corte e costura. Após a montagem do protótipo e sua aprovação, os moldes retornam à modelagem para serem graduados.

3 Termo utilizado para descrever o espaçamento dos tecidos em relação ao corpo humano. Este espaçamento é obtido com o acréscimo de medidas nas linhas de circunferência do corpo a partir das medidas ergonômicas que devem ser calculadas e distribuídas proporcionalmente nos moldes.

4 Pequena sobra de tecido costurado pelo avesso da roupa que se estreita até seu total desaparecimento (formando um triângulo), usada para adaptar os tecidos às curvas do corpo humano. 
Independentemente da técnica que fará uso, é imprescindível que o estudante, o designer ou o pesquisador de moda compreenda o seu real "objeto" de estudo: o corpo humano vivo, para então chegar em como (método) desenvolver suas vestimentas.

\begin{abstract}
O design de moda consiste numa tênue separação entre o corpo e o tecido que o corpo habita como uma epiderme externa, uma segunda pele. $\mathrm{O}$ tecido envolve o corpo e demarca a linha e a forma proposta pela modelagem que o distancia completa ou parcialmente da textura da pele; esta sutil tensão, interna à dinâmica constitutiva do traje é imediatamente percebida como efeito de sentido no olhar do outro, que vê. O olhar adquire uma conotação tátil importante na imagem e na leitura de moda. É justamente o olhar e o tato que sensorialmente encontram-se vinculados ao vestir. É o corpo que responde esteticamente e que interage na performance do sujeito quando em uso de determinada textura ou quando em contato tátil corporal com tipologias de tecidos. A gestualidade, a postura e o timbre da voz são características que oscilam quando em processo de comunicação e leitura tátil que se desenvolve no contato entre corpo e textura. (CASTILHO, 2010, p. 130).
\end{abstract}

\title{
3.1 Modelagem Cartesiana para artigos do vestuário
}

A modelagem cartesiana ${ }^{5}$, é uma técnica de modelagem plana em escala real, aplicada para a construção de artigos do vestuário. Sua linguagem é composta por diretrizes básicas da matemática e da geometria analítica, que usa o sistema de coordenadas ( $x$ e y) que formam - plano cartesiano $^{6}$ para a estruturação bidimensional de figuras geometrizadas, proporcionando a construção de diagramas bidimensionais que mantenham a exatidão das medidas da estrutura física humana com linguagem lógica e de fácil interpretação para ser modelada em papel. A linguagem de modelagem cartesiana manual apresenta a associação na planificação de moldes obtidos através de técnicas de moulage, relacionando o eixo "y" do plano cartesiano ao mesmo sentido do fio do toile ${ }^{7}$, que segue o eixo central do corpo em estudo. Os sistemas de modelagem do vestuário digital CAD/CAM, fazem uso da mesma linguagem empregada, fato que facilita a compreensão e aplicação da metodologia de modelagem cartesiana em outros níveis de conhecimento.

5 THEIS, Mara Rubia. Modelagem Cartesiana para artigos do vestuário: metodologia e aplicação prática. IFSC, Jaraguá do Sul, SC. 2011, 200p. Apostila didática que apresenta a metodologia completa, desde o desenvolvimento do diagrama das principais peças base do vestuário bases: a saia, a calça e a blusa, a inserção de margens de costura, o desenvolvimento de cós e seus acabamentos. Cada artigo do vestuário é apresentado com um passo - a - passo ilustrado e descritivo, com dicas importantes junto aos itens modelados, incluindo a visualização do plano de corte, sugestão de tecidos e máquinas para confeccioná-los, seguindo como bases para o desenvolvimento dos demais artigos do vestuário.

6 Concebido por René Descartes como forma de localizar pontos num determinado espaço, o plano cartesiano consiste em dois eixos (retas) perpendiculares, sendo o sentido horizontal chamado de eixo das abscissas (eixo " $x$ ") e o sentido vertical, de eixo das ordenadas (eixo " $y$ "). Ambos têm valores positivos e negativos. O encontro destes eixos forma um ângulo reto $\left(90^{\circ}\right)$ gerando um ponto de Origem e os espaços formados pelo plano são denominados quadrantes.

7 Tecido usado na moulage, que deve ter características semelhantes ao tecido empregado no produto final (DUBURG; TOL, 2012). 
A modelagem cartesiana pode ser aplicada no desenvolvimento de moldes de todas as faixas etárias, gênero humano ou biótipo físico. A estrutura básica inicial para construção de diagramas de moldes, considerando um corpo simétrico, é formada pelos eixos " $x$ " e " $y$ " de maneira a formar o $4^{\circ}$ quadrante do plano cartesiano. $O$ ponto de origem é denominado ponto zero "0", e serve como referência para aplicar as medidas em centímetros e relacionálas com o marco zero das réguas (Fig. 1).

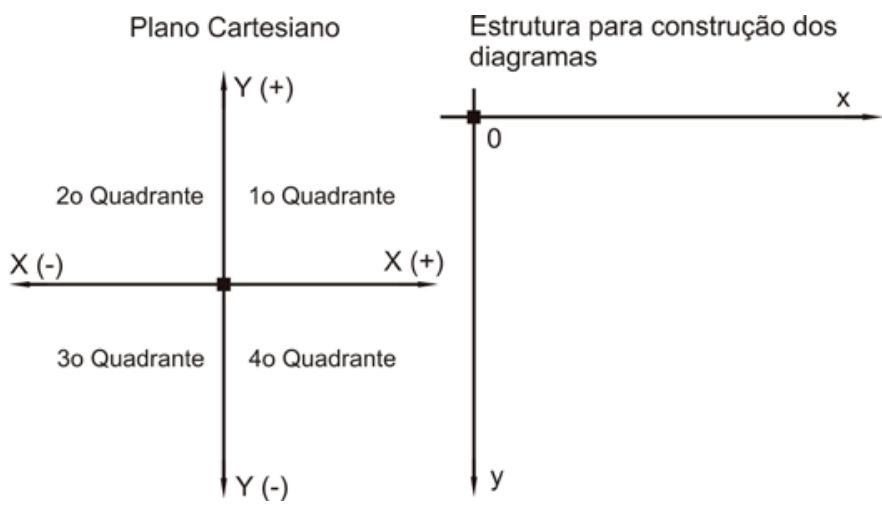

Figura 1: plano cartesiano e estrutura inicial de diagramas Fonte: acervo próprio

As medidas fundamentais, obtidas a partir das medidas de larguras e circunferências do corpo humano, são aplicadas sobre o eixo " $x$ " (abscissa), e as medidas de altura e comprimentos são aplicadas sobre o eixo "y" (ordenada). As medidas complementares, obtidas com a mensuração das partes do corpo, são calculadas a partir de fórmulas obtidas através dos estudos de proporção anatômica e aplicadas proporcionalmente sobre os eixos "x" e "y".

\subsection{Modelagem cartesiana aplicada ao desenvolvimento da blusa}

Segundo Castellani (2003, p.481), blusa é a vestimenta para a parte superior do corpo que cobre todo o tronco, podendo ser utilizada por homens, mulheres e crianças, e pode ter mangas ou não, golas, abotoamentos, pode ser decorada com aviamentos, aplicações e possuir estampas variadas.

Para a construção do diagrama da blusa básica com mangas e modelagem anatômica, são utilizadas medidas fundamentais (circunferência do pescoço, largura das costas, largura do ombro, circunferência do braço, altura do busto, distância do busto entre mamilos, circunferência do busto, altura do mamilo, medida entre mamilos, raio do seio, altura da cintura, circunferência da cintura, circunferência do quadril e altura do quadril) e medidas complementares (altura da cava $-1 / 2$ da largura das costas $+2 \mathrm{~cm}$, altura da cintura, decote, queda de ombro, altura do quadril e altura de cava), representados na Figura 2.

Resumidamente, a construção da base dos diagramas inicia a partir da estrutura do $4^{\circ}$ quadrante do plano cartesiano. Marca-se o ponto de intersecção entre os eixos " $x$ " e " $y$ " identificando-o com "0" zero. O diagrama base é o desenho bidimensional do corpo: a partir 
deste pode ser acrescentada a costura para teste de vestibilidade que, após a aprovação, servirá como base para interpretação de outros modelos, como blusas, casacos e vestidos.
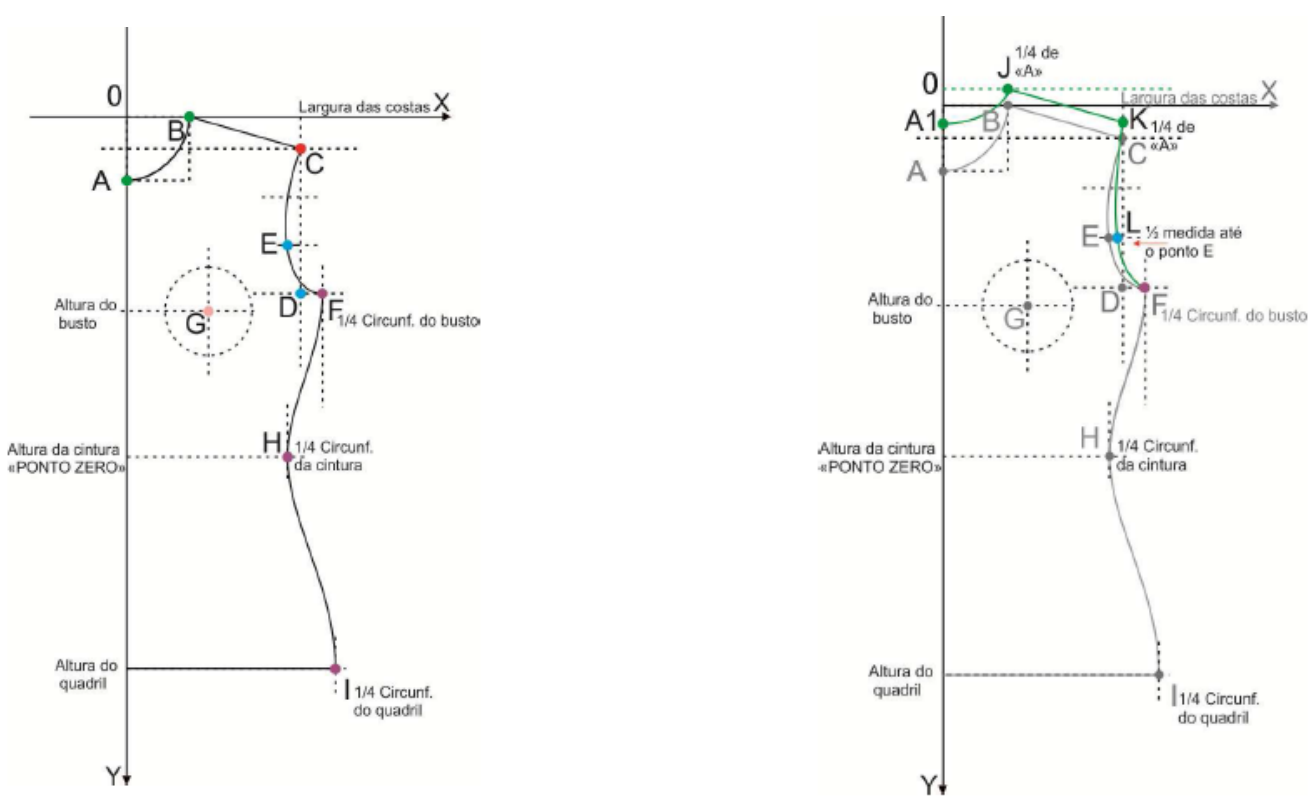

Figura 2: diagrama da blusa ergonômica, frente e costas

Fonte: acervo próprio

A construção da manga é feita a partir do desenho dos contornos dos moldes frente e costa da blusa. Unidos pela lateral da cava, é marcado como ponto zero do plano cartesiano (Fig. 3) e obtida a medida dos perímetros das cavas da frente e costa da blusa. A altura da cabeça da manga equivale a $1 / 3$ do perímetro das cavas subtraído em $10 \%$ de sua medida (para conforto de vestibilidade). A distância entre o ponto Ay desta marcação até o ponto $D$ forma o comprimento do braço. O molde desta manga é base para o desenvolvimento e interpretação de outros modelos, aplicando franzimentos, pregas, recortes de variados comprimentos. 


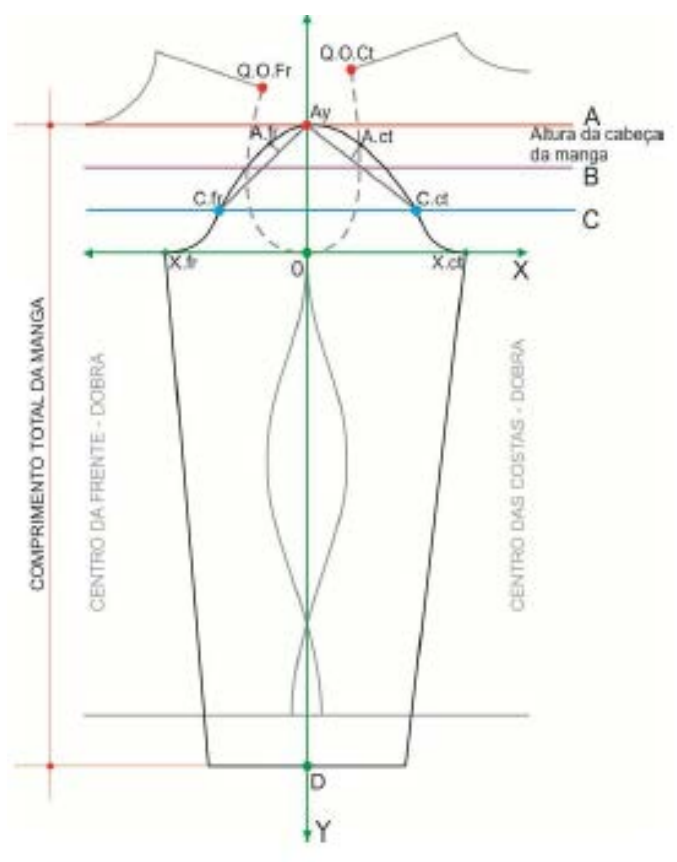

Figura 3: diagrama da manga para blusa ergonômica Fonte: acervo próprio

\subsection{Modelagem cartesiana aplicada ao desenvolvimento da calça}

A parte inferior do tronco pode ser revestida por uma calça, construída a partir das medidas anatômicas do corpo. Peça do vestuário, que desce da cintura aos pés e cobre separadamente as pernas, apresentando diferentes comprimentos a cada modelo (CASTELLANI, 2003, p. 486), a calça é artigo típico do vestuário masculino desde a antiguidade e passou a ser usada por mulheres no início do século XX. Na sociedade contemporânea, é um dos artigos mais populares, podendo ter variações de modelo com recortes, adereços, comprimentos, bolsos, abotoamentos, largura de barra e altura de cintura.

Para a construção do diagrama da calça básica anatômica com pernas retas (Fig. 4), são utilizadas como medidas fundamentais a circunferência da cintura, a circunferência do quadril e o comprimento das pernas. Como medidas complementares, são usadas a altura do gancho, o cálculo da largura do gancho e o cálculo da altura do joelho. 
Assim como para a modelagem da blusa, a base do diagrama da calça inicia a partir da estrutura do $4^{\circ}$ quadrante do plano cartesiano, e, após teste e aprovação, servirá como base para interpretação de outros modelos de calças com formas, comprimentos e proporções variados.
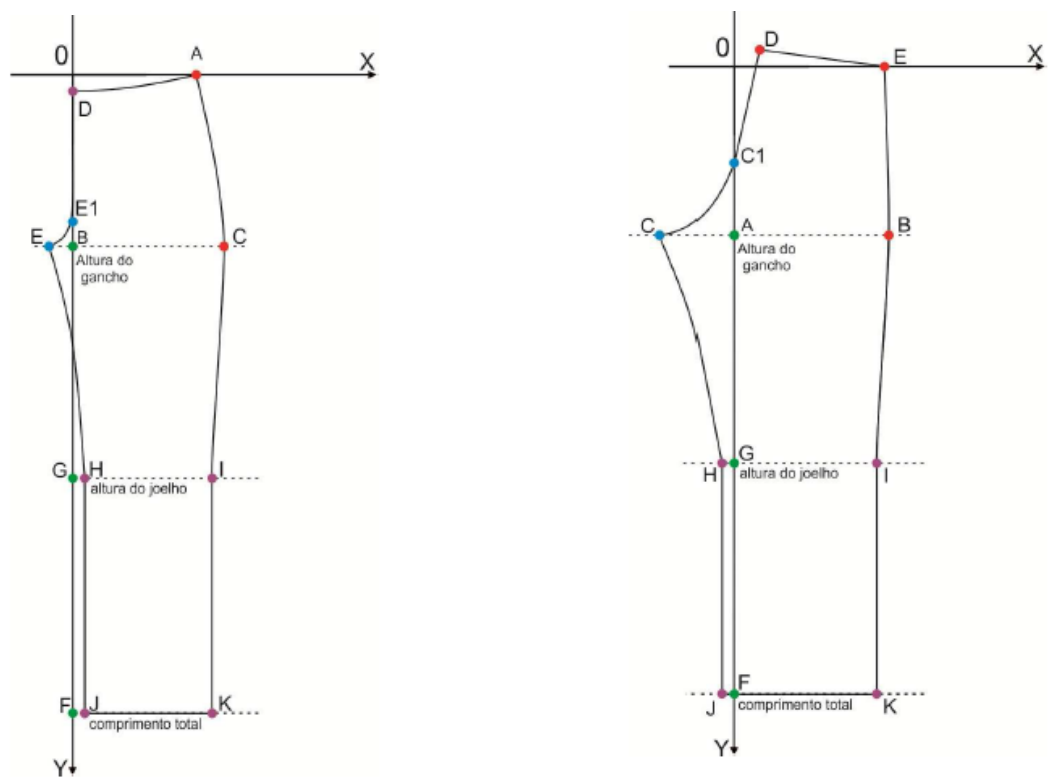

Figura 4: diagrama da calça, frente e costas

Fonte: acervo próprio

\section{MODELAGEM DOS FIGURINOS PARA O GRUPO DE DANÇA DA APAE}

O projeto de extensão que envolveu servidores e alunos do Instituto Federal de Educação, Ciência e Tecnologia - IFSC e a Associação de Pais e Amigos do Excepcionais - APAE de Jaraguá do Sul surgiu com o objetivo de desenvolver figurinos de dança ergonomicamente planejados e com modelagem adequada aos biótipos dos 23 bailarinos do grupo de dança da APAE. Os bailarinos atendidos são portadores de necessidades específicas como hemiplegia, paraplegia, distúrbios psicológicos e Síndrome de Down, e possuem biótipos corporais com amplas variações anatômicas. As medidas antropométricas de cada um deles foram obtidas e analisadas individualmente, fato que permitiu a construção dos diagramas de cada um dos bailarinos. As modelagens foram desenvolvidas através das técnicas de modelagem plana (Modelagem Cartesiana) e moulage, conforme a necessidade e identificação do melhor método para adequar os figurinos de dança aos biótipos de seus usuários.

Segundo relatos da equipe técnica da APAE, dentro do organismo da pessoa com deficiência a música e a dança tornam-se canais que possibilitam que sejam trabalhados aspectos relevantes nas funções do organismo, sejam elas psíquicas, pedagógicas, artísticas ou emocionais, e contribuem para a superação de muitas de suas limitações e a 
integração social. O design de moda deve contribuir nestes trabalhos não apenas por meio da complementação do aspecto lúdico destas atividades, mas também por meio da disponibilização de vestimentas que auxiliem na melhoria da performance dos educandos bailarinos através da integração das metodologias interdisciplinares das áreas de criação, desenho, modelagem, ergonomia e costura.

\subsection{Processo criativo e elementos do design}

A coleção de figurinos de dança foi subdividida em três categorias: andantes, cadeirantes e solo. O objetivo principal era de ressaltar os talentos, alegria e individualidades dos bailarinos do grupo com interferência de técnicas de pintura como forma de construção da identidade individual e das faces grupo (Fig. 5), ressaltadas no fundo musical "Marias" do cantor Ricky Martin. Entre as referências utilizadas durante o processo de pesquisa destacam-se: o retorno da arte ao mundo da moda através do estilo "artsy" - ilustrações, recortes, sobreposições a partir de referências artísticas; o desfile da marca Prada para o Inverno 2014; as silhuetas da década de 20 e o trabalho surrealista do pintor Salvador Dalí. Como inspiração de identidade nacional para o desenvolvimento das diversas identidades deste projeto, buscamos referência no trabalho de Ronaldo Fraga e no colorido do filme "Rio 2", do qual fora extraída uma música para os cadeirantes.

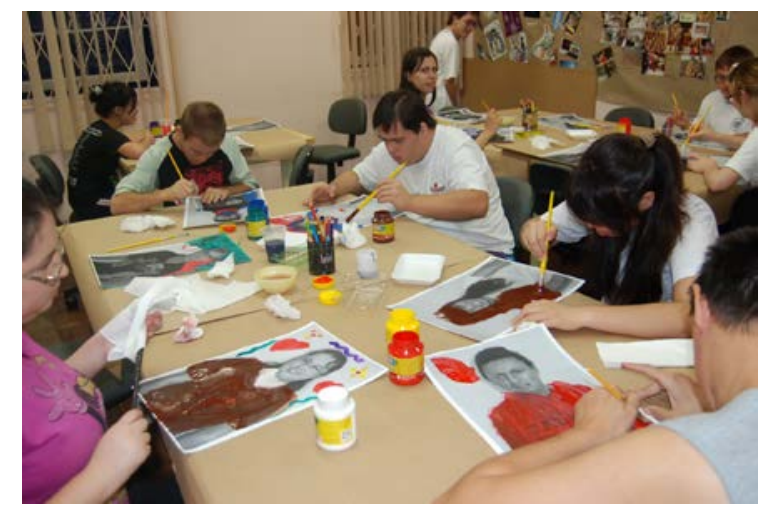

Figura 5: atividade artística de pintura do auto retrato Fonte: acervo próprio

A partir do painel de inspiração e da leitura das pinturas de seus retratos desenhamos os figurinos, sendo os elementos do design: formas - as silhuetas geométricas, simples o retângulo e trapézio especialmente; linhas traduzidas em recortes e apliques (de acordo com a necessidade), as matérias-primas foram doadas, resíduos de tecidos finos, ressaltando a importância da sustentabilidade formando um criativo e rico quebra cabeças; as texturas e as cores foram selecionadas a partir da escolha dos bailarinos nos autorretratos individuais e na harmonização da composição de cada dupla. Essas obras foram traduzidas em caricaturas, gestos e símbolos de cada dupla em suas vestes.

Todos participaram ativamente na apresentação dos desenhos e na aprovação dos croquis, das provas do protótipos (eram em material unicor, tonalidades claras e neutras), da análise dos comprimentos, formas e detalhes. As cores e caricaturas foram aplicadas no figurino 
oficial, contribuindo para a construção das modelagens desenvolvidas especialmente para cada biotipo, em especial observando os pontos de articulação como ombros e joelhos, tornando-os confortáveis e em harmonia com as questões estéticas e ergonômicas que envolveram a construção dos figurinos.

Destaque para as mangas dos vestidos, blusas e camisas: importante ponto de articulação nos movimentos de dança, especialmente os portadores da Síndrome de Down apresentam o diâmetro dos bíceps maiores, sendo assim, tiveram a construção da cabeça da mangas mais baixas, assim, matematicamente proporcionaram a largura adequada da manga na região do bíceps. Essas mangas foram construídas em tecidos leves como rendas, devorês, musselinas, tafetá cristal, dentre outros; os vestidos e blusas femininas com mangas curtas; para o masculino, a escolha foram camisas com mangas longas amplas que permitiram a movimentação com liberdade e ao mesmo tempo uma linguagem de homogeneização de formas desses corpos com destaque para a individualidade através das cores, bordados e aplicações.

\section{CONCLUSÕES}

Este projeto traz a vivência, um estudo de caso, que relata a importância de observar as diferenciações dos corpos através de ferramentas técnicas e metodológicas do design de moda, a antropometria, ergonomia, pesquisa, criação.

A metodologia de modelagem cartesiana, através de sua linguagem matemática simplificada da tridimensionalidade do corpo transportada para o papel em formas bidimensionais, estimula o estudo prático do corpo a ser revestido, algumas vezes com ferramentas da moulage, técnicas de alfaiataria, da análise antropométrica e aplicabilidade de conceitos ergonômicos, um conjunto que impulsiona o êxito na construção eficaz de peças do vestuário.

Esse segunda pele iniciou-se do traçado em grafite do estudo dos corpos, e, como telas em branco, foram moldadas, tomaram formatos de vestidos, tops, blusas, saias, calças e camisas que tinham a função maior de acomodar, abraçar os corpos com conforto, serem fáceis no manuseio em vestir e despir; mas em transpor a identidade, a individualidade especial entre iguais, para uma plateia tão diversa, que em um barulhento silêncio transbordou a linguagem iluminada, multicolorida e alegre em suas texturas, adornos, bordados, apliques.

A oportunidade de trabalhar o desenvolvimentos desta coleção de figurinos de dança com a equipe da APAE local, alunos e equipe técnica, e perceber na prática a profundidade da afirmação "de o corpo ser a junção do físico e psicológico". Do quanto o design de moda pode contribuir com a construção da identidade, de cada ser, criando novas conscientizações sobre o belo e o prazer de ver o outro, de se ver materializado, além de sua própria imaginação. Ver além do corpo físico. Esse fora o desafio ao atender 23 pessoas que almejavam ser vistos, não por compaixão ou dó pela plateia do festival de dança, mas expor o lado talentoso, apaixonado, livre, leve, inocente, colorido, quase infantil que existe nestes corpos, que por terem configurações corpóreas não aceitas pela maioria da sociedade, exclusões iniciadas desde muito cedo, pelos mais próximos muitas vezes, a família. O resultado final, a apresentação do grupo com seu figurino ergonomicamente 
planejado, na formalidade foi alcançada, mas, o processo foi imensuravelmente maior, mais rico, acima de qualquer expectativa; houve sinergia, criação coletiva, inclusão visceral, interação total com a participação ativa do grupo de bailarinos e equipe técnica, desde a criação, pesquisa, desenvolvimento, produção e apresentação.

Essas referências foram registradas através de um sketchbook e dos painéis de inspiração, ferramentas utilizadas no processo criativo do design, sendo que os bailarinos participaram de todo o processo, desde a criação do tema com a intervenção da expressão artística para escolha de cores e sugestão de materiais, ressaltando suas individualidades e identidades. Ao final desses dez meses de um rico trabalho desenvolvido em equipe, destacamos a importância da construção criativa da diversidade coletiva, que trouxe a reflexão do tempo, o atendimento diferenciado para o público diferenciado, o ritmo de vida e envolvimento emocional, e a consciência do papel social da moda.

\section{REFERÊNCIAS BIBLIOGRÁFICAS}

BOUERI, José Jorge. Sob Medida: antropometria, projeto e modelagem. In: BADUY, Dorotéia. Design de moda: olhares diversos. São Paulo: Estação das Letras e Cores, 2008.

CASTELLANI, Regina Maria. Moda ilustrada de A a Z. Barueri: Manole, 2003.

CASTILHO, Kathia. Moda e Linguagem. São Paulo: Editora Anhembi Morumbi, 2004.

CASTILHO, Kathia; VICENTINI, Claudia Garcia. O corte, a costura, o proceso e o projeto de moda no re-design do corpo. In: OLIVEIRA, Ana Claudia de; CASTILHO, Kathia (orgs.). Corpo e moda: por uma compreensão do contemporáneo. Barueri: Estação das Letras e Cores, 2010.

DUBURG, Anette; TOL, Rixt van der. Moulage: arte e técnica no design de moda. Porto Alegre: Bookman, 2012.

IIDA, Itiro. Ergonomia: projeto e produção. 2.ed. São Paulo: Edgard Blücher, 2005.

GRAVE, Maria de Fátima. A moda-vestuário e a ergonomia do hemiplégico. São Paulo: Escrituras, 2010.

NEVES, Érica P.; PASCHORELLI, Luís C.; MENEZES, Marizilda dos Santos. Moda e ergonomia: contribuição emocional à percepção do vestuário. Anais $14^{\circ}$ Congresso Internacional de Ergonomia e Usabilidade de Interfaces Humano - Tecnologia - Produto, Informações, Ambiente Construído e Transporte. Joinville, SC. 2014.

SABRÁ, Flávio. Modelagem: tecnologia em produção do vestuário. São Paulo: Estação das Letras e Cores, 2009.

TREPTOW, Doris. Inventando Moda: planejamento de coleção. 4.ed. Brusque: D. Treptow, 2007. 